\title{
Challenges in Investigating Trafficking of Migrant Workers for Labour Exploitation: Case Study
}

\author{
Roma Ranasinghe
}

\author{
Freelance Researcher, Sri Lanka
}

\begin{abstract}
This paper examines the phenomenon of Human Trafficking for Labour Exploitation of Sri Lankan migrant workers abroad. Labour trafficking is a form of modern-day slavery in which individuals are recruited or transported to perform labour or services through the use of force, fraud or coercion and under the threat of some kind of penalty. Over the years, foreign employment has generated substantial inflows of remittances and acted as a safety valve for local unemployment and has also opened up overseas employment opportunities for many women who may not have been active in the local labour force, though in low paid occupations such as domestic work. Some Sri Lankan men, women, and children who migrate to the Middle East, Asia-including Southeast Asia and Afghanistan-Europe, and the United States to work in the construction, garment and domestic service sectors are victims of forced labour. This study will focus on a selected sample of cases reported to the Criminal Investigations Department (CID) of Sri Lanka Police, on Trafficking of migrants for labour exploitation. The data was collected from operational case files and interviews with senior investigating officers. Part I of this study discusses the introduction to human trafficking, the definition and the legal framework pertaining to human trafficking in Sri Lanka. Part II, will illustrate the case studies with the three major stages in the trafficking process: recruitment, control, and exploitation. The key challenges associated with investigating this crime will be discussed in Part III of this study. The paper ultimately concludes the officers' recommendations for future investigation of cases.
\end{abstract}

Keywords: Human Trafficking, Labour exploitation, migrant workers, Challenges, Investigation

\section{Background}

Over the years, foreign employment has generated substantial inflows of remittances and contributed to the development of livelihoods in Sri Lanka, particularly among low income households. Having scrutinized the Government reports for last few years, around 200,000 migrants emigrate annually from Sri Lanka for semi or low skilled jobs abroad.

There are many factors that drive men and women into migrant employment; these include large economic disparities, the absence of a regular living wage and lack of equitable social and economic policy for women. On the other hand, migrant workers encounter many challenges, principally during the recruitment process. These include, but are not limited to: high costs of migration, deception regarding the terms and conditions of employment, limited access to information on safe recruitment and employment options, abuse, and other unscrupulous recruitment practices. Despite the regulatory mechanisms imposed by the government, desperate migrants, knowingly or unknowingly, take risks to migrate for employment without proper documents, often aided by recruiters and intermediaries. Recruiters and employers take full advantage of the weak negotiating status and low bargaining powers of potential migrant workers.

The recruitment process is either formal through recruiting agency network and or through informal intermediately network. The intermediary network is linked to the agency network since they source workers for agencies for a fee. There is a third dimension - namely the recruiting agency counterparts in host countries. There are intermediaries in host countries as well, most of whom are Sri Lankan nationals living and working 
there, who lure migrant prospects at home to take alternate and often irregular pathways to migrate- bypassing the conventional agency system and even the mandatory registration process of the SLBFE.

Irregular and undocumented migration for work overseas exposes migrant workers vulnerable to trafficking and exploitative labour, including commercial sexual exploitation. The reported cases revealed that the migrant workers experienced violations of their labour rights through psychological and physical harassment, isolation, non-payment of agreed wages, debt bondage to placement agencies and involuntary servitude.

\section{Scope of the study}

The scope of this study is to discuss the phenomena of human trafficking in general and trafficking of migrant workers for labour exploitation in specific. As well as to find out the key challenges associated with investigating this crime and the recommendations to overcome the challenges.

\section{Methodology}

Trafficking of migrant workers was chosen as the main focus because it is an area where exploitation takes place overseas and investigating the crime has become a major challenge. For this study, the sample was selected from the cases reported to the Criminal Investigations Department (CID) of Sri Lanka Police, on Trafficking of migrants for labour exploitation. The data was collected from operational case files and interviews with senior investigating officers.

\section{Part I}

\section{Introduction to Human Trafficking}

Trafficking in human beings is a severe crime and constitutes a gross violation of human rights, which is an international predicament and poses one of the most serious threats to human rights and human security. Human Trafficking is defined as the acquisition and sale of human beings for the purpose of sexual slavery, forced labour or commercial exploitation for the trafficker or other. In other words, it is a form of modern day slavery and one of the greatest human rights challenges of our time. Since it is complex and multifaceted in nature, it has become one of the most transnational organized crimes to combat. The first agreed, internationally binding definition of the term can be found in the UN Protocol to Prevent, Suppress and Punish Trafficking in Persons, Especially Women and Children, supplementing the UN Convention against Transnational Organised Crime (Palermo Protocol), adopted on 15 November 2000. The Palermo Protocol defines trafficking in persons as:

“(...) the recruitment, transportation, transfer, harbouring or receipt of persons, by means of the threat or use of force or other forms coercion, of abduction of fraud, of deception, of the abuse of power of a position of vulnerability or of the giving or receiving of payment or benefits to achieve the consent of a person having control over another person, for the purpose of exploitation, Exploitation shall include, at a minimum, the exploitation of the prostitution of others or other forms of sexual exploitation, forced labour or services, slavery or practices similar to slavery, servitude or the removal of organs."

The definition provides that three elements must be present in any individual case of trafficking for labour exploitation to be established: Act, Means and Purpose. This study discusses trafficking for the purpose of labour exploitation. Labour trafficking is a form of modern-day slavery in which individuals are recruited or transported to perform labour or services through the use of force, fraud or coercion and under the threat of some kind of penalty. In addition, the person has not offered himself/herself voluntarily for the activity in question. The International Labour Organization (ILO) uses the expression 'forced labour' instead of the word 'trafficking' and estimates that 24.9 million people are victims of forced labour. It further reports that out of the 24.9 million people trapped in forced labour, 16 million people are exploited in the private sector such as 
domestic work, construction or agriculture; 4.8 million persons in forced sexual exploitation, and 4 million persons in forced labour imposed by state authorities. ${ }^{\text {ii }}$

Looking at the definition of forced labour contained in the 1930 ILO Convention No 29, Article 2(1) states that for the purposes of this convention the term forced or compulsory labour shall mean 'all work or service which is exacted from any person under the menace of any penalty and for which the said person has not offered himself voluntarily'. According to the ILO, this definition contains three main elements:

'First, some form of work or service must be provided by the individual concerned to a third party; second, the work is performed under the threat of a penalty, which can take various forms, whether physical, psychological, financial or other; and third, the work is undertaken involuntarily, meaning that the person either became engaged in the activity against their free will or, once engaged, finds that he or she cannot leave the job with a reasonable period of notice, and without forgoing payment or other entitlements ${ }^{\mathrm{iii}}$

Forced labour is thus not defined by the nature of the work being performed (which can be either legal or illegal under national law), but rather by the nature of the relationship between the person performing the work and the person exacting the work'.

\section{Legal Framework in Sri Lanka}

Sri Lanka ratified the United Nations Convention on Transnational Organized Crime (UNTOC) in September 2006. The supplementary protocol to the UNTOC, the Palermo Protocol; the Protocol to Prevent, Suppress and Punish Trafficking in Persons, especially Women and Children, was signed in December 2000 and ratified in June 2015. The ILO Convention on Forced Labour No 29 was also ratified by Sri Lanka in 1950.

Anti-trafficking legislation existed in Sri Lanka even before the Palermo Protocol was signed. The concept of Human Trafficking was introduced to the law of the country for the first time in 1995 with the enactment of the Penal Code (Amendment) Act, No.22. The definition of trafficking in Section 360C of the Penal Code underwent further changes with the 2006 Amendment to the Penal Code. These changes brought the provisions in the Penal Code more in line with the Palermo Protocol.

Under sec 360(c) of the amendment Act No 16 of 2006;

Whoever

(a) buys, sells or barters or instigates another person to buy, sell or barter any person or does anything to promote, facilitate or induce the buying, selling or bartering of any person for money or other consideration;

(b) recruits, transports, transfers, harbours or receives any person or does any other act by the use of threat, force, fraud, deception or inducement or by exploiting the vulnerability of another for the purpose of securing forced or compulsory labour or services, slavery, servitude, the removal of organs, prostitution or other forms of sexual exploitation or any other act which constitutes an offence under any law;

(c) recruits, transports, transfers, harbours or receives a child or does any other act whether with or without the consent of such child for the purpose of securing forced or compulsory labour or 
services, slavery, servitude or the removal of organs, prostitution or other forms of sexual exploitation, or any other act which constitutes an offence under any law, Shall be guilty of the offence of trafficking. ${ }^{\text {iv }}$

The Penal Code Amendment is a major reform which introduced a comprehensive definition of trafficking to the criminal law of Sri Lanka. Sri Lanka is a source country for migration as people in Sri Lanka seek employment abroad. Hence a national policy on migration that promises to prevent the trafficking of Sri Lankan migrants is already in place.

Being party to many conventions on labour, Sri Lanka also has ratified the Convention on Migrant Workers as well as 8 Core ILO Conventions protecting the rights of workers.

\section{Part II}

The cases discussed in this study are cases directly reported to the CID and cases referred to the CID by the Sri Lanka Foreign Employment Bureau (SLBFE) and the Ministry of Foreign Affairs (MFA). From the interviews with the officers investigating the cases, it was revealed that all the cases reported on potential labour trafficking were external and involved migrant workers.

When cases were reported to the SLBFE and MFA from foreign missions, the cases are screened to identify human trafficking elements. Once identified, the cases are referred to the CID for investigation.

This study focus on 4 suspected cases of labour trafficking referred to the CID during the period 2017-2018 by the SLBFE and the MFA.

\section{Case 1}

A Sri Lankan national residing in Malaysia recruited 41 males through his female agent in Sri Lanka. These 41 males were from different locations in the country. All of them were recruited for employment in a chocolate company and were promised a monthly salary of Rs.120,000/- . The job opportunities were not advertised in the papers but spread through personal contacts. None of them signed a contract of employment and they travelled on tourist visa. Out of the 41, 21 travelled on forged visas. Each had to pay Rs.300,000/- in cash, where 130,000/- was paid to the female agent in Sri Lanka and the balance 170,000/- was to be handed over to the main recruiter residing in Malaysia. When they arrived in Malaysia, the recruiter received them at the airport and they were provided with food and accommodation. Their passports were taken into the custody of the recruiter. After some time they were informed that the chocolate company is not established and therefore they were placed in three different places. Some were sent to metal industries and others were placed in construction sites. Their passports were returned to them when they were sent to other places for employment. They were not paid a salary and worked for long hours with poor working conditions. They were only paid an allowance for meals and accommodated in poor living conditions. When they demanded their salary they were informed by the employer that they were being sold to him.

The families of the victims complained to the female recruiter in Sri Lanka, and as a result of the pressure put on her by the victims' families, all 41 victims were sent back home. The expense of the airline tickets were borne by the female recruiter's husband.

Taking note of the definition as mentioned above, it is noticeable that there are three main components or elements namely: the act, the means and the purpose.

Firstly the act of recruitment has taken place by the Sri Lankan woman. Secondly they were promised false jobs and a lucrative salary. Moreover, they travelled on tourist visa and some on forged visas instead of employment visa. Fulfilling the second element through deception. 
Finally the victims were sold to a metal industry and construction site where they were forced to work without a salary under poor working conditions.

Initially, their passports were in the custody of the main suspect but later the passports were handed over to the victims after being sold to other places of employment. Although they were promised jobs in a chocolate factory for a monthly salary of Rs. 120,000 /- none of them received neither the promised job nor the salary. Fulfilling the third element purpose through exploitation.

\section{Case 2}

The victim of this case is a 37 year old woman married and divorced with two children and remarried. She has 02 children from the second marriage. After a conflict with the second husband she came to Colombo and stayed with her sister-in-law. While she was there, a neighbour arranged a job for the victim in Malaysia to work as a housemaid. The neighbour's friend X, in Malaysia arranged visa and she was received by her at the airport and her passport was also taken into X's custody. She was provided with food and accommodation at X's house. Although the victim was promised the job to work as a housemaid, she was employed part time in several houses and hotels. Husband of X escorted her to places to work on part time. She worked for one and a half months without the salary being paid. In order to get the victim back home her husband deposited Rs.340, 000/to X's bank account in Sri Lanka and she returned home.

Looking at the three elements; firstly the victim was recruited by $\mathrm{X}$ who was introduced to her by her neighbour, lured into a job with a lucrative salary, fulfilling the first and the second elements. Finally she was forced to work in different places without a salary instead of promised job as housemaid. Fulfilling the third element, exploitation.

\section{Case 3}

A person from the South of Sri Lanka recruited 12 Sri Lankan males in the fishing industry in South Africa. Each person paid a sum of Rs.50, 000/- as the recruitment fee. The recruiter as the partner of the company provided letters to obtain visa. The 12 victims self registered at the Sri Lanka Bureau for Foreign Employment (SLBFE) submitting the letter from the company and visa. Although they were promised jobs in South Africa in a big fishing vessel, they were taken to Somaliland and sold to Y for US\$ 46,000/-. They were forced to go fishing in small boats daily with armed men. They were constantly threatened and forced to work. No food was provided to them; instead they were given an allowance of \$200-250 for all 3 meals where they had to cook their meals. While working they met an IOM (International Organization for Migration) staff on the beach who rescued them after informing the Police. The 12 men were repatriated after 3 months working in Somaliland without any salary being paid.

Firstly, the 12 men were recruited by a Sri Lankan man. They were promised jobs in a big fishing vessel in South Africa with a monthly salary of $\$ 400$, but they were sent to Somaliland instead. Fulfilling the first element Act of recruitment, second element means of deception. Thirdly, they were forced to work under fear and threat, without being paid a salary, under poor living conditions fulfilling the third element, purpose of exploitation.

\section{Case 4}

Two Sri Lankan men were recruited by a shipping company on a paper advertisement for crew members for a commercial vessel in Malaysia. The 02 males were holders of National Vocational Qualification (NVQ) certificate and qualified as assistant deck yard engineers. Although they had the Continuous Discharge Certificates (CDC), they were not registered at the Merchant Shipping Secretariat of the Ministry of Ports and Shipping. The company promised a monthly salary of US\$350 each and air tickets and visa were also arranged, although for employment they travelled on visit visas. Each of them paid a sum of Rs. 325,000/- as recruitment 
fee to the recruiter. The recruiter ' $R$ ' was a Sri Lankan national and represented himself as a partner of the said shipping company in Malaysia. The employment contract signed by the two men does not specifically mention the description of the vessel they were to be employed in. When the two men arrived in Malaysia, ' $R$ ' provided them with accommodation and their passports were confiscated by him. They were later to put to Battala boats (boats to transport timber). When the two men refused to work they were told to pay Rs.600, 000/-.

In looking at the elements, firstly they were recruited by ' $\mathrm{R}$ ' on a paper advertisement and a recruitment fee was also charged from each fulfilling the first element Act. Secondly they were promised jobs in a commercial vessel with a monthly salary of US\$350, whereas they were employed in Battalas and no salary was paid, fulfilling the second element of deception and third element exploitation.

Above noted Cases of labour trafficking occurred in very diverse settings, in private households, in supply chains, through a process of individual and private based recruitment process or recruitment through intermediaries and recruitment agencies.

Notably, the migrant workers in the cases discussed above had incurred a series of costs linked to their recruitment, such as high payments to their job broker/recruiting agency, transportation cost such as air tickets and visas and other transaction costs. In addition, systematic underpayment of wages and artificial deductions from wages, inflated accommodation and food charges and, forced overtime and other forms of excessive work which were inadequately remunerated. It is apparent that in all the cases discussed above the cost of coercion is present, which is a clear indication of financial coercion.

The most common method used to control the victims in all four cases was the confiscation of the victims' passports by the trafficker. In addition to that, fear, threat and intimidation were also used against the victims.

\section{Part III}

In this part the author wishes to discuss the challenges in investigating cases of Human Trafficking for Labour Exploitation. All the four selected cases discussed above are external trafficking cases where the exploitation of migrant workers took place in the destination country.

The victims' statement about the exploitation they suffered at the hands of their traffickers is the primary source of evidence in all four cases mentioned above.

Secondly, as victims are the primary source of evidence in human trafficking investigations, securing victim cooperation is critical. According to the investigation officers, victims' cooperation is the most common challenges faced by the investigating officers in investigating human trafficking cases. Majority of the victims of human trafficking cases in Sri Lanka are often reluctant to cooperate in criminal investigation or proceed with the prosecution of the case due to social stigma, economic reasons where the victims' family is reliant on their income for survival. Quite often they see that prosecuting against the trafficker is a waste of time and money.

Referring to Case 1, there are 41 suspected victims, making it a challenging task to get statements from all victims. The victims are from different locations in the country making it a time consuming task. Some are reluctant to give a statement and proceed with the case due to social stigma and economic reasons as noted above. Trafficking cases often involve lengthy investigations that can leave victims dropping out halfway through the investigation or during prosecution as they see that it is not worth their time and effort, and rather leave the country again for employment. This is common especially in trafficking cases where there are several victims involved in one scenario, such as in Case 1.

Issues in arresting the main suspect in Case 1; the main suspect of this case is a Sri Lankan national residing in Malaysia. In order to arrest the main suspect, it is required by the victims to make a complaint to the police in Malaysia. For that purpose the suspected victims have to be kept in Malaysia which is a time consuming 
process. Moreover, the victims prefer to return to the country, rather than going through the cumbersome procedures in complaining to the police in the destination country. The main suspect is continuing his recruitments using different identities. The risk is that the recruitment continues until they are arrested.

In certain situations as in Case 2, due to complicated life situations of the victims, the investigation officers found contacting the victim a challenging task. The victim in Case 2 lived in several locations of the country as a result of her multiple marriages.

In instances where money transactions with the traffickers through banks takes place, the investigation officers find it a challenging task to visit the particular banks to obtain the banks statements. This is also a time consuming task.

Use of pseudo names, and bogus addresses by the traffickers is also a challenge in investigating trafficking cases.

Victims bonding with the trafficker is seen when the traffickers provide the air tickets to return home. Sometimes the traffickers are also from the same neighbourhood or village. Consequent to the threats and the bonding, the victims become reluctant to complain to the authorities and law enforcement agencies.

\section{Conclusion and Recommendations}

The cases discussed in this paper were trafficking of migrant workers for labour exploitation referred to the CID by SLBFE. Apparently in all four cases the victims were irregular migrants. They travelled on visit visas or visas that were forged. None of the victims in the cases above registered themselves at the Sri Lanka Bureau for Foreign Employment except in Case 3. It was observed that in certain cases the victims signed employment contracts which were vague and tricky and others did not sign a contract at all. The cost of coercion is present in all four cases, where the migrant workers or the victims were financially coerced as noted above.

The common challenge for the investigating officers was collecting evidence with regard to exploitation as the exploitation has taken place in the destination country. Hence the primary source of evidence is the victims' statement, and securing the cooperation of victims is critical.

Measures for certain challenges noted in this study have already being addressed by the government of Sri Lanka.

In November 2017, the Parliament of Sri Lanka amended Section 31(1) of the Assistance to and Protection of Victims of Crime and Witnesses Act, No. 4 of 2015 by enacting "Assistance to and Protection of Victims of crime and Witnesses (Amendment) Act, no. 27 of $2017^{\prime \prime}$.

This important amendment introduced provisions to record statements within Sri Lanka as well as outside Sri Lanka. One of the salient features of the amendment is the provisions that provides for Sri Lankan expatriates to give evidence through Sri Lankan missions in the countries they currently live. This addresses the difficulties encountered by the Police Officers in taking statements from victims who are outside Sri Lanka.

Although the amendment is in place, it is not implemented yet.

No job order approvals are granted by the SLBFE for the countries where no Sri Lanka Missions are operated without attestation of those documents by the Ministry of Foreign Affairs or Chamber of Commerce of the country of employment. This system is currently in operation. This is a notable step taken by the SLBFE subsequent to the case where 12 migrant workers trafficked to Somaliland where there is no Sri Lankan mission. 


\section{Recommendations}

In instances where the recruiter is residing in the destination country, it is recommended for the victims to lodge a complaint to the Police of the destination country before returning home. This will enable the law enforcement authorities in the destination country to arrest the suspects, prosecute and deport. In most of the cases the victims return without making a complaint to the Police of the destination country.

It was also recommended to educate the victims, that even if they commit an offence they will not be prosecuted for the offences they committed. .

Lack of institutional and human resources. In order to further strengthen the counter trafficking mechanisms of the Sri Lanka Police Department, the "Human Trafficking and Smuggling Investigations Bureau" was established in October 2016. This specialized unit with trained officers is supervised by an officer in the rank of Assistant Superintendent of Police (ASP).

The said bureau of the Criminal Investigation Department (CID) operates under the directives given by the Director, Senior Deputy Inspector General and The Deputy Inspector General of the CID. The above noted cases were referred to the HTSIB for investigation. It is recommended to further strengthen this bureau with more trained officers and resources. The limited human resource in the bureau is seen as a challenge when investigating trafficking cases involving multiple victims.

Training of investigating officers on the new amendments to the laws and update them with the new rules and regulations being introduced by the authorities such as SLBFE, immigration and Victim and Wittiness Protection Authority.

Best practices for acquiring and utilizing corroborating evidence in human trafficking cases, including improving interviews with human trafficking victims.

Create a network with INGOS, NGOs and CDO (Community Development Organizations) to provide sustainable livelihood support to victims of trafficking in order to empower victims through the process of assisting with the prosecution of the cases.

\section{References}

${ }^{\mathrm{i}}$ United Nations Office of the High Commissioner for Human Rights (2000) Protocol to Prevent, Suppress and Punish Trafficking in Persons Especially Women and Children, supplementing the United Nations Convention against Transnational Organized Crime.

[Online].Availablefrom:https://www.ohchr.org/en/professionalinterest/pages/protocoltraffickinginpersons.aspx[ Accessed 29.10.2019]

ii International Labour Organization [Online].Available from: https://www.ilo.org/global/topics/forcedlabour/lang--en/index.htm[Accessed

\subsubsection{9]}

iii C029 - Forced Labour Convention, 1930 (No. 29) [Online]. Available from: https://www.ilo.org/dyn/normlex/en/f?p=NORMLEXPUB:12100:0::NO::P12100_ILO_CODE:C029 [Accessed 03/11/2019]

iv Amendment to the Penal Code of Sri Lanka Act No.16 of 2006 